\title{
SEFARDÍES TETUANÍES EN LA SABANA DEL CHACO AUSTRAL, ARGENTINA
}

\section{Eduardo Fortunato Muscar Benasayag}

Mucho se ha escrito sobre la diáspora del pueblo judío por todo el orbe en sus dos vertientes étnicas/geográficas: sefardíes/ashkenazims, y siempre en esta indisoluble asociación del pueblo judío resulta trascendente rescatar para la memoria activa/colectiva hechos que resultan significativos y que no hacen más que aportar luz sobre aquellas pequeñas historias, aunque, siempre grandes y épicas para quienes las emprendieron. Este documento, que se inscribe en la tradición oral, es la epopeya de un grupo concreto que se suma a otros millones de personas insertas en grupos étnicos o de nacionalidades concretas, que cruzaron el ancho mar para "hacer las américas". A menudo se toparon con destinos más crueles que el que les tocó vivir en las naciones de las que tuvieron que emigrar en busca de mejores condiciones económicos o de calidad de vida. Son, en su mayoría, grupos de la misma nacionalidad o religión que aportaron mucho a las sociedades en las que se han asimilado, mimetizado o simbiotizado con el correr de los años. Resulta fructífero que estos pequeños aportes sirvan como base para recomponer el amplio puzzle de la diáspora contemporánea y preservar para las generaciones futuras los éxitos, los fracasos, las penas o las angustias por la que tuvieron que transitar nuestros antepasados para lograr una patria, un terruño, un lugar en el mundo donde adaptarse, no sin penurias, y donde dieron lo mejor de sí para contribuir a la consolidación de las nacientes repúblicas latinoamericanas en las que encontraron cobijo y comprensión. A veces, algunas excepciones eclipsaron y frustraron el ideal de un imaginario pletórico de alegorías transmitidos por los precursores que ya habían puesto su destino a merced de la mítica América.

V.S. Naipaul, expresa: "la mayoría de nosotros, conoce a sus padres, a sus abuelos de los que ha nacido. Pero nuestros orígenes (¿los nuestros también?) son más lejanos, nos remontamos hasta el infinito. En nuestra sangre, en nuestros huesos y en nuestro cerebro acarreamos la memoria de miles de seres. A veces, incluso podemos ser extraños para nosotros mismos", sentencia asumible para nuestro pueblo disperso por el mundo, como otros, tal vez, pero de nuestras raíces, de nuestro grito ancestral de unidad, de no abandono, de los avatares que nos hicieron más o menos vulnerables, surgen historias como la que escribo. También, Jorge L. Borges en su Arte Poética esboza un sentimiento hecho palabra y que nos acerca al objetivo de este testimonio: "A pesar de que la vida de un hombre se componga de miles y miles de momentos y días, esos muchos instantes y esos muchos días pueden reducirse a uno solo: el momento en que el hombre averigua quién es, cuando se ve cara a cara consigo mismo"; pregunta esta última que ayuda, por otra parte, a no reducirse 
solo al presente, al ahora mismo, sino a una más larga distancia en el tiempo y en el espacio. Cuando llega este momento podremos preguntarnos, quiénes somos, averiguar de dónde venimos, tratando de prolongar la trayectoria de nuestras vidas, indagar sobre nuestro entorno próximo y lejano; ¿a quién? a nuestros progenitores, a las personas más próximos y afines a nuestros sentimientos. En definitiva, remontarnos retrospectivamente en el tiempo y poder llegar hasta donde el límite del recuerdo, hasta donde los óbices construyan una barrera infranqueable, más allá de donde la memoria colectiva tiene sus límites.

Este nota que presento resultó del relato transcripto de las conversaciones grabadas a Meri Benasayag, hija de tetuaníes, con más de 97 años de vida y que nos lega con la ayuda de otros miembros de la familia un testamento vivo que no debe fenecer y que podrá fortalecer la historia, no solo de nuestro pueblo, para inscribirlo en un país que recibió un aluvión de inmigrantes procedentes de todos los rincones de Europa, Africa y Asia.

El Lugar: La Sabana: es un pueblo que surge a finales del siglo XIX en la Provincia del Chaco, Argentina, bautizado con este nombre por lo que topográficamente representa el espacio donde fue creada; rodeada de humedales o bajos anegables periódicamente, inmersa en un clima subtropical con estación seca, bastante inhóspito, plagada de alimañas y enclavada en el corazón del Gran Chaco Americano, llanura sin límites. No podemos tampoco ignorar lo que de mágico tiene esta región con sus ríos, humedales, vegetación agreste y exuberante, aves y un sin fin de componentes naturales. Hasta los primeros años del siglo XX el poderío invencible de los indígenas asolaba al pueblo, una especie de far west, donde la riqueza de sus bosques cercanos permitieron abrir uno de los tres ciclos económicos chaqueños: el forestal. Hasta allí llegaron miles de personas provenientes de provincias vecinas, -trabajadores-hacheros-, y del extranjero para lucrar con esa actividad y las relacionadas con ella para satisfacer sus necesidades más básicas. Cabecera del ferrocarril, la civilización distaba 120 km, la ciudad de Resistencia, hoy capital de la provincia; se llegaba a ella por tren. A mediados de 1930 la riqueza emanada del quebracho, madera dura y productora de tanino de alta calidad que se exportó a medio mundo, ya estaba menguada, justamente cuando esta especie por su uso irracional se hizo poco rentable. Esta depresión productiva y económica expulsó a los pobladores que antaño habían creído que este recurso era inagotable, quedando el pueblo con su mágico nombre y despoblado de sus mejores hacedores, también muchos otros de la región que por su efímera existencia pasaron a llamarse "pueblos fantasmas". En este pueblo se pasaron tiempos relativamente normales pero también de penurias: los sangrientos ataques de los indios, a veces dirigidos por blancos, las recurrentes inundaciones que duraban varios meses, ciclones o la explotación ejercida por grupos empresariales extranjeros

Tránsito, impacto y adaptación: En el momento de la incursión a estas tierras remotas e ignotas, desde finales del siglo XIX y a principios del XX, inimaginables en las mentes más creativas, el medio de transporte usual era el barco que surcaba pótamos de una interminable red fluvial, el Río Paraná. Embarcaban en Buenos Aires, a más de 1000 km, y abordaban tras varios días de viaje a los puertos de Barranqueras o Corrientes para luego emprender viaje a La Sabana, $120 \mathrm{~km}$ al oeste. La primera impresión sería el ancho y caudaloso río, 
la vegetación de ribera, la planitud sin límites y la escasa o inexistente población. Gran contraste paisajístico. Habían dejado una tierra con montañas, verdes, una ciudad, Tetuán, con historia de gentes y arquitecturas sólidas, con centenas de años que consolidaron una sociedad multirreligiosa, frente a un recién conquistado espacio en medio de la metafórica nada . Habían cambiado ese escenario por un paisaje agreste, con horizonte infinito, una tierra virgen e indómita en trance de ser domada, sin grandes historias, más que la de los indígenas que la habían dominado practicando el nomadismo o seminonadismo. Ellos, los inmigrantes, serían los actores y creadores, en parte, de una historia que se haría más grande $\mathrm{y}$, que comenzaba a forjarse con mayor diversidad cultural. Este primer impacto produjo en muchos de los tetuaníes recién llegados desazón y frustración, no era lo que esperaban de esa América mágica y rica, tan solo era un mito. En cantidad destacada llegaron los sefardíes y, antes de fijar residencia perpetua recalaron en muy diferentes regiones dentro de Argentina o en la vecina Brasil, otros, los menos, volvieron a la tierra de sus ancestros donde vicisitudes inmensurables los había expulsado.

Los primeros en llegar a La Sabana, Fortunato Benasayag con algunos familiares y amigos ya habían probado suerte en otras provincias argentinas, el mito chaqueño de la tierra a conquistar los sedujo ${ }^{1}$. Adaptarse o regresar era la consigna.. La Sabana en proceso de formación/deformación les brindó posibilidades de abrirse camino. En este modesto y polvoriento asentamiento humano todo era precario, casas de madera con techos de zinc, agua de aljibes, mínimos servicios públicos, calles de tierra, abastecida de las mercancías provenientes de Buenos Aires, con servicios prestados por pueblos cercanos/lejanos de la vecina provincia de Santa Fe: Vera, Los Amores, Reconquista o de la misma capital provincial, Resistencia.

Como la sangre tira, pronto van llegando otros conciudadanos que a través de religión, costumbres y lengua en común les permitirá una adaptación más plácida no ausente de incertidumbres. Pronto formaron una pequeña comunidad sefardí, donde la amplia mayoría, 98\% procedía de Tetuán. De los matrimonios arribados o formados en La Sabana nacieron los primeros argentinos. Cabe destacar que un $99 \%$ de las parejas se formaron entre tetuaníes; hubo un solo caso de un matrimonio mixto turco-marroquí y otro inusual, un tetuaní con una cristiana. Concretamente, hallamos un alto grado de matrimonios endogámicos. Posteriormente seguiría esta tendencia con la primera generación de argentinos, por lo menos hasta el momento en que emigran hacia otras ciudades y se encuentran con judíos sefardíes de otros países e incluso asquenazies. A partir de este momento no es una excepción a la regla sino un hecho usual que los matrimonios mixtos se extendieran entre todas las etnias y nacionalidades judías.

La vida en común: En los primeros años, a pesar de ser extraños, se integran al resto de habitantes de origen español pero también de otras naciones europeas. Ellos se consideraban españoles, por ende europeos y, dada la pluralidad étnica pronto se encontraron seguros,

\footnotetext{
${ }^{1}$ Los sefardíes a diferencia del resto de la comunidad judía en su mayoría se dispersaron por los centros urbanos de Argentina, sobre todo los localizados en las provincias de Entre Ríos, Santa Fé, Córdoba, Chaco, Corrientes, entre otras.
} 
aceptados y comenzaron a realizar sus tareas comerciales -buhonería- abasteciendo a los trabajadores forestales, en los obrajes, y a los propios del pueblo. Más tarde abrieron sus propias tiendas. Fueron respetados y respetaron la diversidad de sus vecinos.

En el punto más alto de su apogeo La Sabana tuvo una población que nunca rebasó los 2000 habitantes, he aquí lo más anecdótico de esta historia, cerca de 180, contando ya los hijos nacidos en el pueblo, eran sefardíes procedentes, como ya se dijo, en un $98 \%$ de Tetuán, aportando a la población sabanera aproximadamente un 19\% del total. Hablando con algunos sobrevivientes que habían conocido a mis abuelos, tíos y otros miembros de la comunidad les pregunté cuál era el sentimiento que experimentaban ante un grupo de gentes de distinta religión; se confirmaba lo que comenta mi madre, eran unas personas más dentro del conjunto de habitantes de La Sabana y la convivencia siempre fue normal. Sus ritos, música, comidas, modos de vida en general, eran muy apreciados por todos. Los primero años, sin embargo, practicaban un tanto recelosos las fiestas que marca el calendario hebreo: Pesaj, Rosh Hashana, Yom Kippur, Purim, Janucá, bodas, circuncisiones, tefilines (Bar Mitzbá), Ilulah, entre otras, siempre realizadas en una improvisada sinagoga que funcionaba en la casa de los Forado, en la intimidad del hogar, sin la participación de goys (cristianos), más por pudor que por la intención de formar un gueto en tan minúsculo núcleo urbano. Ya habiendo nacido los primeros retoños chaqueños/argentinos sirvieron como nexo de unión, máxime cuando comenzaron a asistir a la escuela primaria. En este sentido, sobre todo los educadores sentían curiosidad bien intencionada por asistir a algunas de las ceremonias, extremo que siempre fue bien visto por los miembros de la comunidad sefardí, aunque a veces con recelo. Pasados más años se celebraron bodas a la que asistían los miembros más representativos de la sociedad civil, el juez de paz, el director y los maestros de la escuela, el jefe de estación, los miembros rectores del orden urbano y las personas más representativas de la sociedad.

Fueron las bodas las fiestas mas participativas, también otras originales. Durante días preparaban las comidas, postres y dulces con materia procedente de Buenos Aires. Empanadas, pollos y corderos asados, ensaladas de naranjas amargas o remolacha, mazapanes, fishuelas, biszcochos y un sin fin de confituras y mermeladas -jaleas- de naranjas, mandarinas, azahares, berenjenas. En la elaboración participaban varias mujeres y el festejo se celebraba en improvisados salones de fiesta: vaciaban almacenes, despensas o ultramarinos para tal fin. El oficiante procedía, lo mismo que para otras ceremonias de ciudades distantes o en casos extremos la oficiaba un jajanico. El terin, cuando finalizaba Pesah, o las tortillas y demás comidas para romper tani después del ayuno, o la adafina del shabat, fueron recetas bien guardadas y que después se fueron mezclando con otras, en esa simbiosis cultural con la otra mayoría sefardí, pero ya en Resistencia, los turcos. Más tarde la riqueza culinaria se proveyó de recetas provenientes de matrimonios mixtos entre sefardíes tetuaníes, turcos o ashquenazims.

En la vida privada se hablaba la jaquetía, "elemento distintivo" utilizado como una "forma secreta de comunicación"² dialecto que más tarde se convertiría ya no en un código

\footnotetext{
${ }^{2}$ Epstein, D. (1996): Particularidades de la inmigración judeo marroquí y su integración en la sociedad argentina (1890-1910). In SEFARADICA, Nº 11, Buenos Aires, pp.128
} 
para ocultar hechos, confabulaciones, sino en una forma de comunicarse que mantenía vivos los lazos con el pasado cercano. Hoy lo siguen hablando y las personas allegadas que no son sefardíes siempre se quedan con algún vocablo.

Los hombres trabajaban en sus tiendas u oficiaban de viajantes, las mujeres ejercían las labores domésticas. Algunas de ellas habían estudiado en la Alianza Israelita Universal, hablando además del hebreo, la jaquetía, algo de árabe, un correcto español y francés, por lo que se convirtieron en maestras para aquellas personas que no se expresaban correctamente o que eran semianalfabetas. Fue el caso de Rashma Tangir de Benasayag, que además, era escribiente y lectora de cartas con destino a Tetuán o provenientes de allá; continuó más tarde su oficio de profesora particular en Resistencia. Las familias más pudientes empleaban en su casa mujeres, generalmente indígenas o mestizas, para que ayudaran en los quehaceres domésticos. Una de ellas, Rosa, era la mujer del cacique Rostán, blanca cautiva que nunca quiso abandonar su toldería -conjunto de ranchos donde vivían los indios-, también trabajaban hombres indígenas para trozar leña o acarrear agua dulce. Diguidí, hermano de Rostán y ciego deambulaba las calles de La Sabana y se convirtió en personaje popular, sobre todo para los pequeños; sus anécdotas fueron ricas, jocosas y se mantienen hasta el día de hoy entre los hijos, nietos o bisnietos de los sefardíes sabaneros.

Los primeros difuntos eran sepultados en el cementerio hebreo de Vera, Provincia de Santa Fe, más tarde cuando en 1912 se crea el de Resistencia y son trasladados hacia allí por ferrocarril.

En las fiestas patrias, como el 25 de mayo, 9 de julio o el día de la Raza -12 de octubre- participaban con gran regocijo en los actos públicos o en las romerías españolas a la que acudían músicos y bailarines de otras ciudades mezclándose en el gran jolgorio en un espacio público, que no plaza, existente en el pueblo.

Otro indicador de su fácil asimilación/integración lo demuestra el hecho de que a pocos años de su llegada a La Sabana comenzaron a participar activamente en los actos cívicos para elegir concejales municipales (Departamento Electoral de La Sabana) o en calidad de escrutadores (Francisco Forado, 1910), siendo elegidos algunos de ellos miembros del Concejo Municipal (Jacobo Hassan, 1909 con 115 votos sobre 119 votantes, las mujeres por entonces no ejercían el derecho al voto, siendo reelegido en 1910; Isaac Bentolila, 1913; Levy Chocrón, 1922). Cuando el pueblo comenzó a sufrir la decadencia y sus habitantes a emigrar se creó una Comisión de Fomento de la que formaba parte Isaac Bentolila $^{3}$. La amplia mayoría, por otra parte, estaban adscriptos al Partido Radical, que en esos momentos estaba liderado por Hipólito Irigoyen.

Por otra parte, la vida trancurría en torno a las actividades obrajeras, del comercio, de la escuela y al ir y venir del Ferrocarril Francés, cuyas vías y las inmediaciones de la estación era el lugar preferido de los niños de entonces para encuentros fugaces y de esparcimiento ya que el pueblo no contaba con espacios públicos de ocio.

\footnotetext{
${ }^{3}$ Archivo Histórico de la Provincia del Chaco, Carpeta correspondiente a La Sabana
} 
Sin embargo, por más que hayan transcurrido muchos años de pervivencia, los recuerdos y el sentimiento de desarraigo de sus parientes tetuaníes siempre estuvo presente, como lo comenta la musa de esta historia. Era más común en las mujeres que solían pasar por trances de depresión. Esta circunstancia estaba favorecida, sobre todo, por la influencia del entorno, la inseguridad y la incertidumbre por el futuro de los primeros retoños nacidos en suelo argentino y las reminiscencias del lugar de origen, que pese a todo estaba más organizado y contaba con una mejor calidad de vida.

Declive y nuevo éxodo: La fatídica epopeya de la judíos errantes también se cebó con ellos. A partir de 1915 cuando la economía local basada en la actividad forestal y sus subsidiarias comenzó a declinar en forma pausada los tetuaníes y el resto del pueblo comenzaron emigrar a otras ciudades más seguras y con mejores perspectivas, dentro del Chaco, principalmente a su capital Resistencia, o a Villa Angela, Saénz Peña u otras de la provincia de Santa Fe - Vera, Reconquista, Rosario o Santa Fe -; los más osados se radicaron en Buenos Aires, otros, los menos, retornaron a Marruecos. Como la educación de los hijos fue objetivo imperante, muchos adolescentes antecedieron a sus padres yendo a Resistencia para iniciar sus estudios secundarios, sobre todo encaminados al magisterio. Fueron acogidos por paisanos afincados desde siempre en esa ciudad. Luego llegaron los progenitores en busca de trabajo y sosiego. De esa zaga salieron ilustres educadores que se repartieron por los nuevos pueblos que siguieron fundándose en el Chaco impartiendo enseñanza en escuelas públicas de Gancedo, Villa Angela, Las Breñas, Charata o General Pinedo. Destacaron la labor ejercida por docentes que formaron a miles de niños chaqueños, sobre todo en pueblos alejados, habiendo realizado verdaderas proezas en pro de la educación y que hoy son públicamente reconocidas a través de la imposición de sus nombres a escuelas, calles o plazas; citamos entre ellas a Esther Azulay de Fuchs, Raquel Azerrad de Berman, Meri Benasayag de Muscar, Esther Forado de Mellibovsky, Fortuna Chocrón de Echecury4. Esta actividad que por entonces estaba bien remunerada y mejor considerada permitió que muchas economías familiares se vieran reforzadas económicamente. Pero en Resistencia desde la ya fundada Sociedad Israelita Latina del Chaco (1912), cimentaron y coadyuvaron a engrandecer la naciente cultura chaqueña. De esa sociedad surge la primera compañía formal de teatro del Chaco que en 1929 estrenan la obra de teatro Los Mirasoles, comedia de Sánchez Gardel en la sede de la Asociación ${ }^{5}$.

Los nietos de los primeros pobladores de La Sabana ya estudiaron profesiones liberales o se dedicaron al comercio en forma de pequeñas o grandes empresas, a la industria o a otras actividades cubriendo todo el tejido laboral ofrecido por el mercado y pasaron a ocupar destacadas posiciones en el mundo de la política, el arte, la cultura y la economía chaqueñas. Profesores de enseñanza primaria, media y universitaria, directores de música, sin renunciar a sus raíces pero siempre contribuyendo con una sociedad que consideraban

\footnotetext{
${ }^{4}$ Como destacamos antes los hijos de los primeros sefardíes asentados en La Sabana, una vez localizados en la ciudad de Resistencia rompen la endogamia como queda presente en el segundo apellido, precedido de que indica la relación matrimonial

5 Pompert de Valenzuela, Ma . C. (2001): Antecedentes de la Actividad Teatral en Resistencia, In Diario Norte, 29/7/2001, pp. 8-9
} 
suya como la de cualquier otro descendiente de inmigrante, no es para menos en un país formado por un alud inmigratorio que conoce su punto más alto a partir de 1850 y se extiende hasta después de la Segunda Guerra Mundial.

Cuando toda la población de origen sefardí de La Sabana fue obligada a la dispersión por los motivos apuntados la misma comenzó a concentrarse, en su mayoría en Resistencia. La diferencia era abismal, la misma estaba dotada de todos los servicios mínimos indispensables, escuelas, hospitales, teatros, cine, estaba experimentando un cambio radical en los prolegómenos de iniciar su segundo ciclo económico, el algodonero. Una ciudad bordeada por dos ríos afluentes del Paraná, el riacho Arazá y el Río Negro y a $10 \mathrm{~km}$ del puerto de Barranqueras, siempre expuesta a inundaciones periódicas. Una ciudad trazada en damero con una plaza central de 4 has de la que nacían cuatro avenidas que tomaban contacto con otras tantas de circunvalación, cuatro plazas se sumaban al resto de representaciones urbanas. Todo estos alicientes hizo más fuerte el ánimo de aquellos tetuaníes que habían vivido en el impersonal conglomerado humano de antaño.

La asimilación a la nueva ciudad que los acogía fue similar a la de La Sabana pero con más elementos motivadores. Pronto contarían con una línea de ferrocarril que los comunicaría con Buenos Aires y otros pueblos del Chaco. La sensación de aislamiento anterior había desaparecido. La nueva ciudad tenía temporadas de ebullición artística: compañías de teatro, orquestas, asociaciones culturales, hacían más amena la tranquila vida provinciana. No hubo diferencias ni para unos ni para otros. En Estampas Chaqueñas, revista que reflejaba la vida social y económica de la provincia del Chaco siempre tuvo entre sus protagonistas a algún miembro de la colectividad sefardí. En las primeras décadas del siglo XX se funda en Resistencia el primer centro sefardí el cual tenía una doble función: religiosa y social. Un bello edificio con reminiscencias mozárabes que mantiene intacta su fisonomía hasta la actualidad. Ya habían arribado a la ciudad un importante contingente de polacos, rusos...que más tarde erigirían su propia sinagoga anexo a un centro educativo y social y más tarde su cementerio. La cercanía con la ciudad de Corrientes, capital de la provincia homónima, también permitió que se estrecharan lazos de cooperación o que algunas familias se fusionaran por bodas entre correntinos y chaqueños.

Por razones económicas, en el presente, la Sinagoga Sefardí solo se dedica al culto, mientras que la otra a eventos sociales y culturales. Ambas comunidades tienen un papel destacado en la ciudad y participan de todos los eventos provinciales y nacionales: sociales, culturales, políticos y económicos. Lo que lograron los sefardíes pioneros de La Sabana fue un ejemplo de convivencia, solidaridad y que más tarde se plasmó definitivamente en esta ciudad que hoy alcanza una población de 350.000. Las fiestas tradicionales tienen amplia difusión y los días más sagrados son respetados otorgando día festivos a los judíos, tónica que se mantiene a nivel nacional.

Transcurridos más de cien años de aquella epopeya, La Sabana se constituyó en un paraje embrionario en el que hundieron sus raíces tetuaníes pioneros y actores de una maravillosa gesta, no exenta de avatares, junto a la pléyade de inmigrantes de otros rincones del orbe, pero que allá en la distancia convertida en un espacio mítico dentro de la historia 
chaqueña, donde el imaginario construyó metáforas de vida. Tierra perdida en el tiempo pero presente en la mente de los que seguimos pregonando para no abandonar ni olvidar nuestros orígenes como forma de mantener viva la historia más llena de alegrías que de fracasos. Hoy los aún supervivientes recuerdan con satisfacción los viejos tiempos vividos dando fuerza al aforismo: todo tiempo pasado fue mejor. 